\title{
Analysis of the root canal configuration and C-shaped canal frequency of mandibular second molars: a cone beam computed tomography study
}

\author{
M. Tassoker, S. Sener \\ Department of Oral and Maxillofacial Radiology, Necmettin Erbakan University, Faculty of Dentistry, Konya, Turkey
}

[Received: 22 February 2018; Accepted: 9 April 2018]

Background: Mandibular second molars frequently show variation in root canal configurations. The patients with C-shaped canals are quite challenging in dental practice. C-shaped canals have a poor prognosis in terms of debridement, obturation, and restoration. The aim of this study was to investigate the root canal configuration of mandibular second molar teeth and to determine the frequency of C-shaped canals in mandibular second molars.

Materials and methods: We designed a retrospective study using cone beam computed tomography (CBCT) images and 256 CBCT images were retrieved from the archived records of Necmettin Erbakan University Faculty of Dentistry, Konya, Turkey. The root canal configurations were evaluated according to Vertucci's classification and C-shaped canal configurations were identified using the method of Fan et al. The frequency in percentages was calculated for C-shaped canals in CBCT scans.

Results: Of the 444 mandibular second molars, the most frequent canal morphology in the mesial roots was Vertucci type IV (40.3\%), followed by type II (27.5\%). The distal roots were predominantly type I (92.9\%), followed by types III (3.5\%) and II (2.5\%). Forty-seven (10.6\%) teeth had C-shaped canals.

Conclusions: Clinicians should be concerned about the different types of canal configurations. Knowledge of these anatomical variations will facilitate the endodontic practice. (Folia Morphol 2018; 77, 4: 752-757)

Key words: C-shaped canal, cone beam computed tomography, mandibular second molars

\section{INTRODUCTION}

Knowledge of root canal anatomy and variations between different populations is necessary for clinicians to conduct successful endodontic treatment $[7,30]$. Mandibular second molars have a wide variety of root canal configurations [2]. The C-shaped root canal configuration was first described by Cooke and Cox in 1979 [3]. This canal configuration is mostly found in the mandibular second molars $[11,15,30]$ but can also be seen in other teeth groups [15]. The C-shaped canal morphology is of clinical importance that they have a poor prognosis in terms of cleaning, obturation, and shaping $[2,11,15,23]$.

Manning [14] proposed that the failure of the adhesion of the Hertwig's epithelial root sheath to the buccal or lingual root surface was the main aetiolog-

Address for correspondence: Dr. M. Tassoker and Dr. S. Sener, Necmettin Erbakan University, Faculty of Dentistry, Department of Oral and Maxillofacial Radiology, 42050 Konya, Turkey, tel: +90332 2200025-154 and +90332 2200025-147, e-mail: dishekmelek@gmail.com and ssener@konya.edu.tr

This study was presented in $12^{\text {th }}$ Asian Oral and Maxillofacial Radiology Congress (ACOMFR) 2016 in Thailand. 
ical factor of the C-shaped root canal configuration. The primary morphological characteristic of C-shaped canal is the presence of a fin or web connecting the individual canals $[15,23]$. On the other hand, the gene(s) leading C-shaped root canals in mice are present on either chromosome 5 or 17 [16, 24].

The prevalence of C-shaped mandibular second molar canals has been studied worldwide and has been reported to range from $2.7 \%$ [27] to $44.5 \%$ [8] depending on the population. It is well accepted that there is a higher prevalence of this configuration in Asia when compared with other populations $[10,15]$ such as Europeans and Americans [9]. Some authors stated that the prevalence of C-shaped canal morphology has been shown to vary significantly by race $[8,10,22]$.

Sectioning method, transparent model method, dye infiltration method, radiography, computed tomography (CT), micro-CT, cone beam CT (CBCT) imaging techniques have been used in the literature to define C-shaped root canal configurations $[2,4,5$, $14,17,22,30]$. Diagnosis of C-shaped canals with two-dimensional imaging methods is challenging $[6,12,23]$ because of the image superimposition [11]. CBCT imaging is a non-invasive method and facilitates the understanding of $C$-shaped canal morphology along the root $[11,23]$. Compared with conventional medical $\mathrm{CT}, \mathrm{CBCT}$ provides lower effective radiation dose, higher resolution and shorter working time [18]. Micro-CT is non-destructive technique and offers up to $2 \mu \mathrm{m}$ resolution compared to CBCT. However, micro-CT method required much more time and it is applicable only in ex vivo studies [21]. Although all methodologies have their own benefits and defects, CBCT is the only technology that enables a good resolution of three-dimensional (3D) images of in vivo studies [15]. This study aimed to investigate the root canal configuration of mandibular second molar teeth and to find out the frequency of C-shaped canals in mandibular second molars.

\section{MATERIALS AND METHODS}

This retrospective radiological study was performed with the approval of the Necmettin Erbakan University Faculty of Dentistry Research Ethics Committee. Furthermore, the analysis was performed within the stipulations laid out by the Declaration of Helsinki (decision no: 2016/011). The study consisted of 256 patients ( 123 males and 133 females) who had undergone $\mathrm{CBCT}$ imaging for diagnostic purposes and treatment planning between 2013 and 2016 years. $\mathrm{CBCT}$ images were retrieved from the archived records of Department of Oral and Maxillofacial Radiology, Necmettin Erbakan University, Faculty of Dentistry, Konya, Turkey.

Teeth with periapical pathologies, resorptions, calcifications, open apices were excluded. Fully developed and untreated (no root fillings, posts or crown restorations) teeth were included in the study [29]. CBCT images of patients were obtained using a 3D Accuitomo $170^{\circledR}$ machine (Morita, Kyoto, Japan). Serial axial, coronal and sagittal CBCT slices were observed by rolling the toolbar from the pulp chamber to the apex. The thickness of the image slices was $1 \mathrm{~mm}$ and the distance between slices was $1 \mathrm{~mm}$. The root canal configurations of mandibular second molars were evaluated according to Vertucci's classification (Fig. 1) [26]. C-shaped canal configurations were classified using the method of Fan et al. [4] (Fig. 2). The frequency in percentages was calculated for C-shaped canals in CBCT scans.

The description of a C-shaped canal morphology meets all of the following three features (Fig. 3):

- fused roots;

- a longitudinal groove on the lingual or buccal surface of the root;

- at least one cross-section of the canal belonging to the $\mathrm{C} 1, \mathrm{C} 2$ or $\mathrm{C} 3$ configuration [4].

All CBCT images were assessed by the same oral and maxillofacial radiologist. Two weeks later, examinations were repeated showing good intra-examiner agreement. The kappa values $(\kappa=1.00)$ reflected excellent intraobserver agreement for root canal morphology and C-shaped canal morphology. All CBCT images were examined in a dark room and in the same computer (Intel ${ }^{\circledR}$ Xeon ${ }^{\circledR}$ E5-2620, $2.0 \mathrm{GHz}$; NVIDIA quadro 2000; 32" Dell T7600 workstation with a resolution of $1280 \times 1024$ pixels, $8 \mathrm{~GB}$ memory, Windows 7 operating system) with the use of the i-Dixel software Ver. 2.0 (J. Morita MFG. Co.).

\section{Statistical analysis}

Statistical analysis was performed by SPSS version 21.0 (Statistical Package for Social Science Inc., Chicago, IL, USA). Data set was analysed using descriptive statistics and Pearson $\chi^{2}$ test. The reliability of data were analysed using the kappa test. $P$ values less than 0.05 was considered to be significant. The kappa coefficient was interpreted as being poor (0), slight (0.01-0.20), fair (0.21-0.40), moderate (0.41-0.60), substantial (0.61-0.80), and almost perfect (0.81-1.0), according to Landis and Koch [13]. 


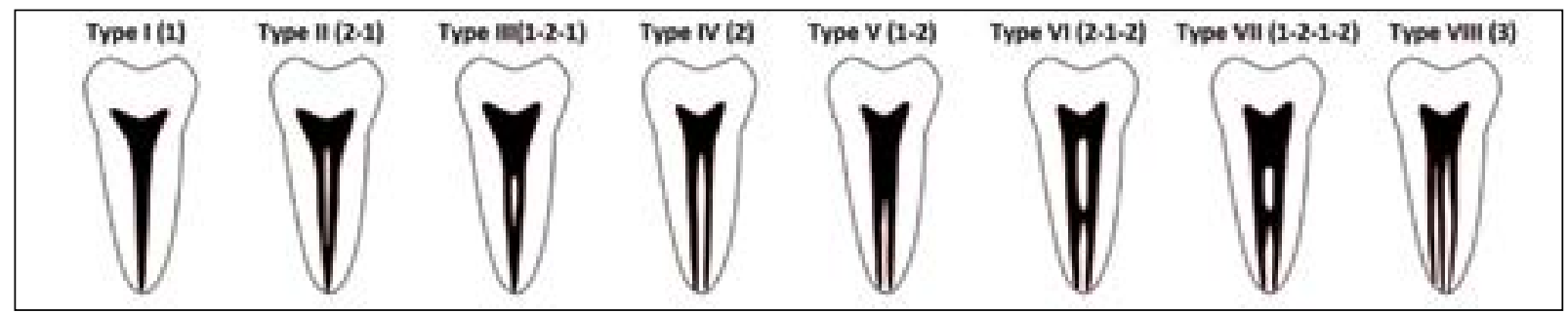

Figure 1. The root canal configurations according to Vertucci [26].

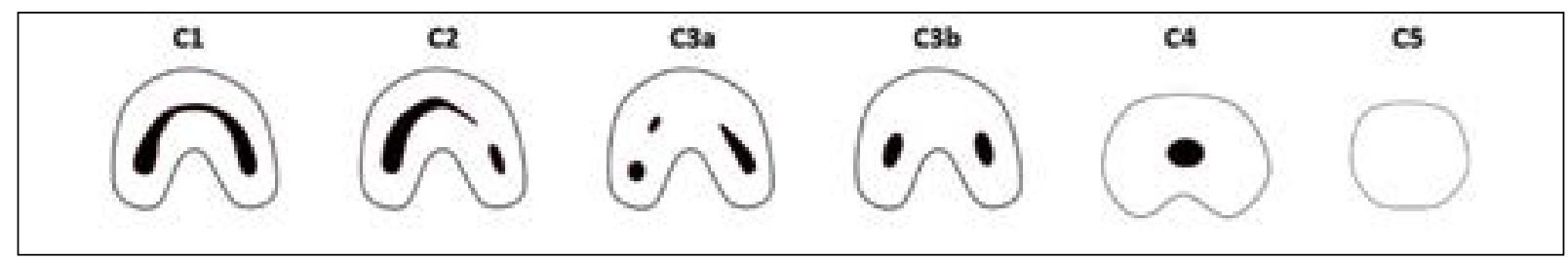

Figure 2. C-shaped root canal configurations according to Fan et al. [4]. C1 — uninterrupted C-shaped canal; C2 — semi-colon shaped canal; $\mathrm{C} 3$ - two or three separate canals; $\mathrm{C} 4$ - only one round or oval canal; $\mathrm{C} 5$ - no observable canal lumen.

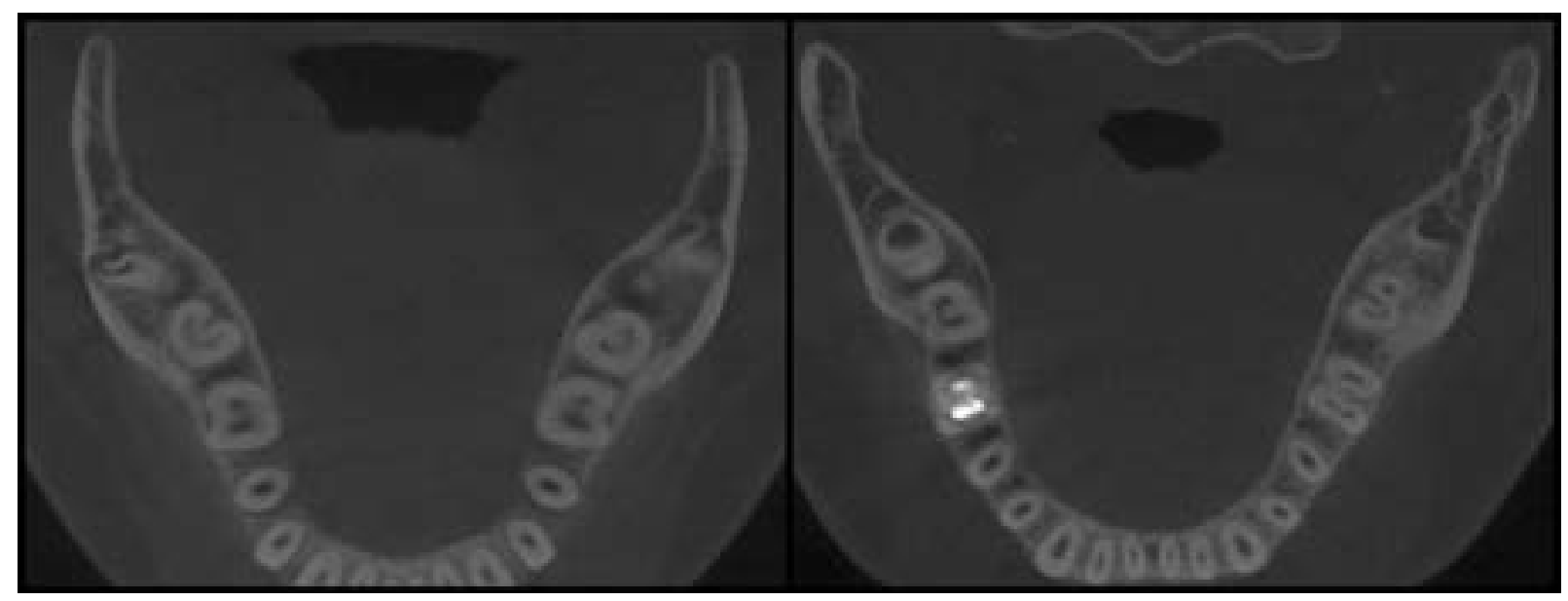

Figure 3. Examples of C-shaped canals.

\section{RESULTS}

With a total of 256 individuals, $48 \%(n=122)$ were males and $52 \%(n=134)$ were females. The mean age of the patients was 32.3 years, ranging from 16 to 80 years. Of the 444 mandibular second molars included, the most frequent canal morphology in the mesial roots was Vertucci type IV ( 2 canals, 2 foramina; $40.3 \%$ ), followed by type II (2 canals, 1 foramen; $27.5 \%)$. The distal roots were predominantly type I (1 canal, 1 foramen; 92.9\%), followed by types III (3.5\%) and II (2.5\%).

Of the 444 mandibular second molars assessed in CBCT images, 47 (10.6\%) teeth had C-shaped root canal morphology and they were all single rooted mandibular second molars. This frequency did not show statistically difference between males and females $(p=0.768, p>0.05)$. The bilateral occurrence of C-shaped canals in mandibular second molars was $88 \%$. The most of canal orifices ( $72 \%$ ) demonstrated C1 canal configuration, followed by C2 type (19\%), and C3 type orifice (9\%).

\section{DISCUSSION}

In this study, the root canal configurations of mandibular second molars were assessed with CBCT. In simple cases, when root canal examination is possible from intraoral periapical radiographs or clinical procedures, the use of $\mathrm{CBCT}$ is not necessary. When abnormal findings are observed on intraoral periapical images and/or clinical setting, it may be impossible 
Table 1. C-shaped canal studies in the literature

\begin{tabular}{llcccc}
\hline Author & Year & Population & Method & Number of teeth & Frequency (\%) \\
\hline Weine et al. [27] & 1988 & Mixed (American) & X-ray & 75 & 2.7 \\
Yang et al. [28] & 1988 & Chinese & Clearing & 581 & 13.3 \\
Lambrianidis et al. [12] & 2001 & Greek & X-ray & 480 & 4.6 \\
Gulabivala et al. [6] & 2002 & Thai & Clearing & 60 & 10 \\
Seo and Park [22] & 2004 & Korean & Sectioning & 96 & 31.3 \\
Seo and Park [22] & 2004 & Korean & X-ray & 272 & 32 \\
Cimilli et al. [2] & 2005 & Turkish & CT & 491 & 8.1 \\
Jin et al. [8] & 2006 & Korean & CT & 220 & 44.5 \\
Rahimi et al. [20] & 2008 & Iranian & Clearing & 139 & 7.2 \\
Zheng et al. [30] & 2011 & Chinese & CBCT & 528 & 38.6 \\
Zhang et al. [29] & 2011 & Chinese & CBCT & 157 & 29 \\
Helcacioglu-Yigit and Sinanoglu [7] & 2013 & Turkish & CBCT & 271 & 8.9 \\
Silva et al. [25] & 2013 & Brazilian & CBCT & 226 & 3.5 \\
Ladeira et al. [11] & 2014 & Brazilian & CBCT & 406 & 15.3 \\
Kim et al. [10] & 2016 & Korean & CBCT & 1920 & 40 \\
Martins et al. [15] & 2016 & Portuguese & CBCT & 1088 & 1465 \\
Shemesh et al. [23] & 2016 & Israeli & CBCT & 983 & 8.5 \\
Pawar et al. [19] & 2017 & Indian & CBCT & CBCT & 4.6 \\
Present study & 2018 & Turkish & 20 & 13.12
\end{tabular}

CBCT — cone beam computed tomography; CT — computed tomography

to evaluate the root canal system effectively. In these situations, CBCT imaging is needed for further diagnosis regarding as low as reasonably achievable principle [29].

The results of this research indicated that mesial roots had a high frequency of Vertucci's type IV $(40.3 \%)$, whilst the majority of distal roots revealed type I (92.9\%) morphology similar to the results of previous studies [6, 10, 29]. Gulabivala et al. [6] reported this trend as a Mongoloid trait. These findings differ from the results of type II dominance in the mesial roots in studies of mixed populations [26, 27]. Clinicians should pay attention for the type IV morphology ( 2 canals, 2 foramina) of the mesial roots regarding the possibility of missing 1 canal [10].

Knowledge of the morphological features of C-shaped canals such as deep grooves that are located buccally or lingually is important. These grooves might lead to strip perforations during biomechanical preparation [7]. Moreover, presence of transverse anastomoses, lateral canals and apical deltas complicate the cleaning and sealing the $C$-shaped canal system in these teeth [2].

The frequency of C-shaped canal morphology in the Turkish population is lower than some other populations [7]. As mentioned before, the frequency of C-shaped canals may reach $44.5 \%$ in Asian populations [8]. In the Middle East, frequency of $7.2 \%$ and $10.6 \%$ for Iranian [20] and Saudi Arabian [1] populations was reported. According to the results of this study, the frequency of C-shaped canal configuration was $10.6 \%$, which is in accordance with the findings of the studies conducted in the Middle East populations. Other frequency findings of several researchers in the literature are given in the Table 1. These differences may be result of the lack of homogeneity between studies, mainly regarding the defining criteria of 'C-shape', discrepancy of the sample size and methodologies (radiographs, tooth sections, clearing, $C B C T, C T$, and micro-CT) $[15,30]$.

Several methods were reported in the literature which investigating the root canal morphology. One of those, micro-CT which is an imaging technique used for in vitro studies, cannot be used clinically yet. Fan et al. [4] examined the morphological characteristics of C-shaped canals with micro-CT. They observed that when a C-shaped canal orifice was observed in the pulp chamber, it may change along the length of the root. As a limitation of this study, examination of C-shaped morphology was done only at canal orifice 
level. Most of canal orifices (72\%) demonstrated C1 canal configuration in our study. C1 and C2 configurations are much more difficult to shape and clean than the C3 and C4 [30].

Zheng et al. [30] evaluated the mandibular second molars at four root levels including canal orifice, coronal, middle and apical third of the root. The results revealed that only $12(5.5 \%)$ teeth did not change canal configuration from the orifice to the apical space. The frequency of C1 and C2 morphologies decreased from the orifice to the apical region, whilst that of $\mathrm{C} 3$ and $\mathrm{C} 4$ increased.

In this study, no statistical relationship was found between gender and the frequency of C-shaped canals. This result in accordance with Zheng et al. [30], Pawar et al. [19] but in contrast with Martins et al. [15]. These differences may be due to the disparities in the ethnic backgrounds of participants and sample size [10].

According to the results of the current study, C-shaped root canal morphology tends to have a bilateral appearance. Majority (88\%) of the C-shaped canals were both seen in right and left arch similar to the results of the studies conducted by Kim et al. [10] in Koreans and Zheng et al. [30] in Chinese population. Therefore, clinicians should consider possible symmetry of the C-shaped canal morphology when treating two homologous molars in the same patient $[10,23]$.

\section{CONCLUSIONS}

As a conclusion, the most frequent root canal configuration in mandibular second molars was characterised by 2 canals, 2 foramina in the mesial roots and 1 canal, 1 foramen in the distal roots. C-shaped canal can be seen unilateral or bilateral and the frequency of C-shaped canals showed no difference between genders. C-shaped canal morphology is not rare in Turkish population and clinician should be aware of this morphology during the treatment procedures. CBCT imaging is the best method to provide 3D nature of the root canal morphology if abnormal findings are observed on intraoral radiographs.

\section{REFERENCES}

1. Al-Fouzan KS. C-shaped root canals in mandibular second molars in a Saudi Arabian population. Int Endod J. 2002; 35(6): 499-504, indexed in Pubmed: 12190906.

2. Cimilli H, Cimilli T, Mumcu G, et al. Spiral computed tomographic demonstration of C-shaped canals in mandibular second molars. Dentomaxillofac Radiol. 2005; 34(3): 164-167, doi: 10.1259/dmfr/64778606, indexed in Pubmed: 15897287.
3. Cooke HG, Cox FL. C-shaped canal configurations in mandibular molars. J Am Dent Assoc. 1979; 99(5): 836-839, indexed in Pubmed: 290680.

4. Fan B, Cheung GSP, Fan M, et al. C-shaped canal system in mandibular second molars: Part I: Anatomical features. J Endod. 2004; 30(12): 899-903, indexed in Pubmed: 15564874.

5. Fan B, Cheung G, Fan M, et al. C-Shaped Canal System in Mandibular Second Molars: Part II: Radiographic Features. J Endod. 2004; 30(12): 904-908, doi: 10.1097/01.don.0000136206.73115.93, indexed in Pubmed: 15564874.

6. Gulabivala $\mathrm{K}$, Opasanon $\mathrm{A}, \mathrm{Ng} \mathrm{YL}$, et al. Root and canal morphology of Thai mandibular molars. Int Endod J. 2002; 35(1): 56-62, indexed in Pubmed: 11853239.

7. Helvacioglu-Yigit $D$, Sinanoglu A. Use of cone-beam computed tomography to evaluate C-shaped root canal systems in mandibular second molars in a Turkish subpopulation: a retrospective study. Int Endod J. 2013; 46(11): 1032-1038, doi: 10.1111/iej.12094, indexed in Pubmed: 23521079.

8. Jin GC, Lee SJ, Roh BD. Anatomical study of C-shaped canals in mandibular second molars by analysis of computed tomography. J Endod. 2006; 32(1): 10-13, doi: 10.1016/j. joen.2005.10.007, indexed in Pubmed: 16410060.

9. Kato $A$, Ziegler $A$, Higuchi N, et al. Aetiology, incidence and morphology of the $\mathrm{C}$-shaped root canal system and its impact on clinical endodontics. Int Endod J. 2014; 47(11): 10121033, doi: 10.1111/iej.12256, indexed in Pubmed: 24483229.

10. Kim SY, Kim BS, Kim Y. Mandibular second molar root canal morphology and variants in a Korean subpopulation. Int Endod J. 2016; 49(2): 136-144, doi: 10.1111/iej.12437, indexed in Pubmed: 25652228.

11. Ladeira DB, Cruz AD, Freitas DQ, et al. Prevalence of C-shaped root canal in a Brazilian subpopulation: a conebeam computed tomography analysis. Braz Oral Res. 2014; 28: 39-45, indexed in Pubmed: 25000603.

12. Lambrianidis T, Lyroudia K, Pandelidou O, et al. Evaluation of periapical radiographs in the recognition of C-shaped mandibular second molars. Int Endod J. 2001; 34(6): 458-462, indexed in Pubmed: 11556513.

13. Landis JR, Koch GG. The measurement of observer agreement for categorical data. Biometrics. 1977; 33(1): 159-174, indexed in Pubmed: 843571.

14. Manning SA. Root canal anatomy of mandibular second molars. Part II. C-shaped canals. Int Endod J. 1990; 23(1): 40-45, indexed in Pubmed: 2391180.

15. Martins JNR, Mata A, Marques D, et al. Prevalence of C-shaped mandibular molars in the Portuguese population evaluated by cone-beam computed tomography. Eur J Dent. 2016; 10(4): 529-535, doi: 10.4103/13057456.195175, indexed in Pubmed: 28042270.

16. Matsune K. Molecular genetic study of the gutter shaped root (GSR) on mouse chromosome 17. J Oral Sci. 2000; 42(1): 21-26, indexed in Pubmed: 10808271.

17. Melton DC, Krell KV, Fuller MW. Anatomical and histological features of $\mathrm{C}$-shaped canals in mandibular second molars. J Endod. 1991; 17(8): 384-388, doi: 10.1016/ S0099-2399(06)81990-4, indexed in Pubmed: 1809802.

18. Patel S, Dawood A, Ford TP, et al. The potential applications of cone beam computed tomography in the management 
of endodontic problems. Int Endod J. 2007; 40(10): 818-830, doi: 10.1111/j.1365-2591.2007.01299.x, indexed in Pubmed: 17697108.

19. Pawar AM, Pawar M, Kfir A, et al. Root canal morphology and variations in mandibular second molar teeth of an Indian population: an in vivo cone-beam computed tomography analysis. Clin Oral Investig. 2017; 21(9): 2801-2809, doi: 10.1007/s00784-017-2082-6, indexed in Pubmed: 28281013.

20. Rahimi S, Shahi S, Lotfi M, et al. Root canal configuration and the prevalence of C-shaped canals in mandibular second molars in an Iranian population. J Oral Sci. 2008; 50(1): 9-13, doi: 10.2334/josnusd.50.9.

21. Seo DG, Gu Y, Yi YA, et al. A biometric study of C-shaped root canal systems in mandibular second molars using cone-beam computed tomography. Int Endod J. 2012; 45(9): 807-814, doi: 10.1111/j.1365-2591.2012.02037.x, indexed in Pubmed: 22432971.

22. Seo MS, Park DS. C-shaped root canals of mandibular second molars in a Korean population: clinical observation and in vitro analysis. Int Endod J. 2004; 37(2): 139-144, indexed in Pubmed: 14871181.

23. Shemesh A, Levin A, Katzenell V, et al. C-shaped canals-prevalence and root canal configuration by cone beam computed tomography evaluation in first and second mandibular molars-a cross-sectional study. Clin Oral Investig. 2017; 21(6): 2039-2044, doi: 10.1007/s00784016-1993-y, indexed in Pubmed: 27844150.
24. Shimizu T. Mapping of a gene causing mouse gutter-shaped tooth root to chromosome 5. Arch Oral Biol. 1999; 44(11): 917-924, indexed in Pubmed: 10580539.

25. Silva EJ, Nejaim Y, Silva AV, et al. Evaluation of root canal configuration of mandibular molars in a Brazilian population by using cone-beam computed tomography: an in vivo study. J Endod. 2013; 39(7): 849-852, doi: 10.1016/j. joen.2013.04.030, indexed in Pubmed: 23791250.

26. Vertucci FJ. Root canal anatomy of the human permanent teeth. Oral Surg Oral Med Oral Pathol. 1984; 58(5): 589-599, indexed in Pubmed: 6595621.

27. Weine FS, Pasiewicz RA, Rice RT. Canal configuration of the mandibular second molar using a clinically oriented in vitro method. J Endod. 1988; 14(5): 207-213, doi: 10.1016/ S0099-2399(88)80171-7, indexed in Pubmed: 3251974.

28. Yang ZP, Yang SF, Lin YC, et al. C-shaped root canals in mandibular second molars in a Chinese population. Endod Dent Traumatol. 1988; 4(4): 160-163, indexed in Pubmed: 3267526.

29. Zhang R, Wang H, Tian YY, et al. Use of cone-beam computed tomography to evaluate root and canal morphology of mandibular molars in Chinese individuals. Int Endod J. 2011; 44(11): 990-999, doi: 10.1111/j.13652591.2011.01904.x, indexed in Pubmed: 21658074.

30. Zheng Q, Zhang L, Zhou X, et al. C-shaped root canal system in mandibular second molars in a Chinese population evaluated by cone-beam computed tomography. Int Endod J. 2011; 44(9): 857-862, doi: 10.1111/j.13652591.2011.01896.x, indexed in Pubmed: 21599707. 